\title{
A Estética da existência e a beleza da vida libertária
}

\author{
CASSIANA LOPES STEPHAN *
}

RESUMO De acordo com Foucault, a estética da existência se distingue (1) da moral cristã, a qual vincula a austeridade ascética à repressão ou ao constrangimento dos desejos, (2) da lógica jurídica do Estado e (3) das leis do mercado. Logo, para Foucault a ética perde potencialidade estética no momento em que a boa vida deixa de ser considerada como uma vida autarquicamente bela e passa a ser concebida em relação à pureza que se adquire pela submissão da vontade ao dever.Nesse sentido, nossa intenção é problematizar o apanágio estético pertinente à arte de viver, tal como interpretado por Michel Foucault, através da caracterização da relação entre o esforço ético concernente à atitude crítica e a constituição de uma vida libertariamente bela. Sendo assim, desenvolveremos a hipótese de que a beleza da vida do esteta não se estabelece através do sacrifício relativo à depuração do corpo e da carne ou à padronização dos desejos, pois, para Michel Foucault, a vida estética seria rigorosamente ética na medida em que concerniria a um esforço crítico e libertário em torno da transfiguração de si mesmo. Palavras-chave Estética da Existência, Arte de viver, Crítica, Beleza Libertária.

RÉsUMÉ D'après Foucault, l'esthétique de l'existence se différencie (1) de la morale chrétienne, laquelle relie l'austérité ascétique à la répression ou à la contrainte des désirs, (2) de la logique juridique de l'État et (3) des lois du marché. Ainsi, selon Foucault l'éthique perd son potentiel esthétique au moment où la bonne vie cesse d'être comprise comme une vie autarciquement belle et passe à être considérée par rapport à la pureté qui est acquise à travers de la soumission de la volonté au devoir. En ce sens, notre intention est de problématiser le caractère esthétique pertinent à l>art de vivre, dont Michel Foucault a interprété par la caractérisation de la relation entre l>effort éthique concernant à l>attitude critique et la création d>une vie belle et libertaire. Par conséquence, nous envisageons développer l>hypothèse selon laquelle la beauté de la vie de l>esthète ne s'établit pas par le sacrifice relatif à la purification du corps et de

* Doutoranda em Filosofia pela Universidade Federal do Paraná (Bolsista CAPES) cassianastephan@yahoo.com.br la chair ou à la normalisation des désirs, car pour Michel Foucault la vie esthétique serait strictement éthique au fur et à mesure qu'elle concernerait à un effort critique et libertaire autour de la transfiguration de soi-même.

мотS-CLÉs Esthétique de l'existence, Art de vivre, Critique, Beauté libertaire. 
Historicamente, a instituição moral definida segundo os termos da codificação e da obediência aos códigos válidos para todos parece se vincular ao esfacelamento da austeridade ética no que tange à constituição autárquica de si mesmo. Mais precisamente, de acordo com Michel Foucault a ética teria perdido o seu potencial estético, característico das filosofias greco-romanas, na medida em que passaria a ser concebida como um campo religioso e jurídico cuja finalidade é a salvação divina ou, posteriormente, o bem-estar social. Nesse sentido, Foucault considera que a estética da existência se distingue radicalmente da moral cristã, cuja austeridade se vincula à repressão e ao constrangimento dos desejos, bem como, a partir da modernidade, à lógica jurídica do Estado e, mais recentemente, às leis do mercado. O objetivo do código cristão seria suprimir o desejo e o prazer das ações humanas, ou seja, a vontade precisaria ser purificada de toda a influência carnal que afasta a humanidade de sua destinação divina. A aplicação compulsória dos códigos cristãos se articularia ao exercício do poder pastoral: por um lado, a eficácia de tal instituição moral depende da autoridade do pastor, o qual é responsável pela salvação no outro mundo do conjunto da comunidade cristã e de cada indivíduo que a compõe. Portanto, o código moral consiste em um instrumento por meio do qual o pastor aproxima a vontade de cada membro do rebanho à vontade divina, já que as leis religiosas manifestam a pureza de uma conduta que alcança um caráter moral quando, de maneira sacrificial, visa suprimir os prazeres e os desejos da carne em virtude da vida em comunhão. Por outro lado, o fortalecimento da autoridade do pastor resulta do aumento do campo de aplicação do código moral, pois a habilidade do pastoreio se vincula a uma atitude de obediência incondicional que se intensifica em relação à expansão do rebanho. Assim, a autoridade do pastor é proporcional ao grau do seu sacrifício, o qual depende do número de pessoas por quem o pastor se sacrifica em vista da salvação no reino dos fins, isto é, depende da quantidade de indivíduos que ele é capaz de assujeitar às leis cristãs. ${ }^{1}$

1 É importante ressaltar que no caso do poder pastoral o sacrifício em relação à salvação do rebanho envolve o sacrifício do pastor e o sacrifício de cada indivíduo que constitui a comunidade cristã, pois todos devem se submeter aos desígnios do destino ou à vontade divina, os quais se manifestam através do código moral. (Cf. FOUCAULT, "Le sujet et le pouvoir”, 2001, p. 1048) 
Ademais, para Foucault a estética da existência parece consistir em uma alternativa à moral moderna que articula a austeridade do código ao jogo entre dever, recompensa e punição socioeducativa e disciplinar. A moral moderna, diferentemente da cristã, não visa suprimir o desejo e o prazer, mas os transforma em bem-estar social, isto é, talvez seja possível afirmar que ela possui como finalidade a adequação do maior número de pessoas à felicidade de tipo burguesa, a qual decorre da garantia de segurança, educação e saúde, tanto à população quanto a cada indivíduo que compõe o Estado moderno. O Estado, assim como o pastor, visa à instauração e à manutenção da vida comunitária ou em comunhão, a qual pode propiciar o aperfeiçoamento da natureza humana que então deixou de se atrelar ao divino, pois na Modernidade o homem passou a ser concebido como um animal laborante, político e social. Conforme Foucault, isso acontece porque "o Estado moderno integrou, sob uma nova forma política, uma velha técnica de poder que nascera nas instituições cristãs. Essa técnica de poder, chamemo-la de poder pastoral.” (FOUCAULT, “Le sujet et le pouvir”, 2001, p. 1048, tradução nossa).

Foucault nos mostra que tanto as razões estatais quanto a lógica cristã do pastoreio possuem um vínculo instrumental com o código moral e o primado da obediência, isto é, o corpo estatal, assim como o pastor da cristandade, parecem exercer e garantir a sua própria autoridade mediante a aplicação de um conjunto de regras de governamento que delimitam o modo de ser dos sujeitos no que concerne ao desejo, ao pensamento e à ação. O primado do código moral ou jurídico serviria ao exercício do poder pastoral que procura salvaguardar a obediência à autoridade divina ou à ordem pública, garantindo-se ainda a docilidade privada. Portanto, o código moral se constitui e se aplica em virtude do exercício de um poder que se outorga legítimo na medida em que se propõe amparado por um saber que pretende determinar de forma absoluta uma verdade acerca da natureza humana. O objetivo da codificação cristã e da codificação jurídico-política moderna seria estabelecer e assegurar a igualdade entre os homens. A obediência e a docilidade correspondem a atitudes que decorrem da submissão da vontade de cada um dos indivíduos às entidades que regem a vida do fiel e a vida do cidadão. Desse modo, talvez seja possível afirmar que a igualdade se instaura em virtude de uma lógica sacrificial ou purificadora, tanto no que concerne à abnegação cristã dos desejos quanto no que tange à moderna padronização da vontade e das formas de aquisição do prazer e do bem-estar. Com efeito, a vida 
dedicada à pureza racional consiste em uma vida devotada à renúncia de si mesmo e à decifração da verdade interior que busca estabelecer a essencialidade da identificação entre o logos divino e o logos humano ou, modernamente, entre as razões do Estado e o entendimento dos cidadãos que constituem determinada população. Do ponto de vista eclesiástico e estatal, portanto, estes sacrifícios consistiriam em táticas que afastariam os membros do rebanho ou do Leviatã do individualismo egoísta, desencadeando a constituição de uma comunidade fraternal, isenta de conflitos, já que fundada no exercício da igualdade absoluta, a qual extinguiria as diferenças na medida em que assujeitaria a vida de todos e de cada indivíduo à vontade divina ou à vontade analítica do Estado moderno. (Cf. FOUCAULT, M. “'Omnes et singulatim’: vers une critique de la raison politique”, 2001, pp.953-980)

Logo, parece que para Foucault a ética perde potencialidade estética no momento em que a boa vida deixa de ser compreendida como uma vida autarquicamente bela e passa a ser concebida em relação à pureza que se adquire pela submissão da vontade ao dever. (Cf. FOUCAULT, “Une esthétique de l'existence”, 2001, p. 1550) Na Antiguidade greco-romana, sobretudo no caso do estoicismo, do epicurismo e do cinismo, a austeridade ética se atrelava ao desejo estético-artesanal de transformar-se a si mesmo, ou melhor, girava em torno da vontade de transformar a própria vida em uma obra de arte. Isso significa que, de modo geral, para estas morais a questão da pureza ética era praticamente marginal. No entanto, a partir da influência do neoplatonismo e do cristianismo sobre a cultura helenístico-romana (Cf. HADOT, I. \& HADOT, P. Apprendre à philosopher dans l'Antiquité, 2004), os exercícios filosóficos adquiriram lentamente um valor purificador que se manifestava por meio da criação de códigos fundados sobre o esquema da integridade física, tendo em vista a depuração da matéria e a igualdade absoluta, pois se concebeu que a natureza humana é única, universal e não histórica. A ascese perdeu então o caráter estético atrelado à constituição da vida autarquicamente bela e adquiriu um caráter sacrificial ou purificador, isto é, a igualdade entre os homens passou a ser garantida no âmbito da comunhão ou da socialização fraternal, a qual decorre da renúncia de si mesmo:

No ascetismo cristão, a questão da pureza se torna cada vez mais importante; é preciso ter controle em relação a si mesmo para que se possa permanecer puro. O problema da virgindade, esse modelo da integridade feminina, torna-se extremamente importante no cristianismo. $\mathrm{O}$ tema da virgindade não tem 
praticamente nada a ver com a moral sexual do ascetismo greco-romano. $\mathrm{O}$ problema é aquele da dominação de si. (...) O paradigma da auto-restrição sexual se torna um paradigma feminino através do tema da pureza e da virgindade que se funda sobre o modelo da integridade física; (...) O problema da moral como estética da existência foi recoberto pelo problema da purificação. O novo si cristão deveria ser examinado constantemente porque esse si abriga a concupiscência e os desejos da carne. A partir desse momento, o si não era mais qualquer coisa a que era preciso construir, mas qualquer coisa a que era preciso renunciar e que era preciso disponibilizar à decifração. Por consequência, entre o paganismo e o cristianismo a oposição não está entre a tolerância e a austeridade, mas entre uma forma de austeridade que está ligada a uma estética da existência e outras formas de austeridade que estão ligadas à necessidade de renunciar a si decifrando a sua própria verdade. (FOUCAULT, 2001, pp. 12241225, tradução nossa)

Efetivamente, as asceses cristãs continuaram a perspectivar o belo. No entanto, para Foucault a vida bela deixou de se vincular à autarquia e passou a se atrelar ao ideal transcendental de pureza. De fato, a relação entre beleza e pureza parece reverberar no transcorrer da história da arte e da filosofia por meio da figuração feminina da virgem dócil e obediente, que manifesta a dignidade moral através da integridade física e espiritual. A beleza assumiria, nesse sentido, um caráter sacro ou mítico, que repercutiria na idolatria à Virgem Maria ou na representação puritana da Vênus, cuja nudez não serve à revelação do corpo, mas sim à manifestação da perfeição e da eternidade da alma que transcende a materialidade da carne. Deste modo, poderíamos afirmar que a beleza puritana, a qual se torna proeminente a partir do cristianismo, advém, em certa medida, da contemplação aristotélica ou da mímesis platônica.Logo, a estética da existência parece ser uma alternativa à moral do código cristão, na medida em que se desvencilha da ideia de uma beleza pura que emerge, já na Antiguidade filosófica, inclusive no estoicismo tardio de Cícero, em relação a uma noção universal, única e não histórica de natureza humana. De fato, o puritanismo é inerente ao conceito de substância humana e esta acepção ontológica repercute historicamente na manifestação de uma lógica sacrificial que determina a forma pela qual os sujeitos se relacionam consigo mesmos, com os outros e com o mundo no âmbito do vigor institucional do cristianismo, mas também no âmbito da filosofia, da filosofia política e no da arte canônicas. 
Sendo assim, a estética da existência parece estabelecer uma relação polêmica e transgressora para com os cânones artísticos, políticos e morais de uma cultura acomodada à submissão a códigos normativos hegemônicos ou ao princípio cristão da obediência incondicional, que impõe a supressão da vontade de cada um em nome da constituição de uma rede de obediências como condição para a salvação. Nesse sentido, no contexto de uma apreciação transhistórica da estética da existência, parece-nos que esta não figura no puritanismo da Virgem com o Menino ${ }^{2}$ ou da Vênus de Urbino $^{3}$, mas sim no escândalo da profana nudez de Olympia ${ }^{4}$, uma prostituta que vive às margens do poder pastoral. (Cf. FOUCAULT, M. La peinture de Manet, 2004, pp.38-40) A beleza do corpo nu de Olympia exprimiria o desejo subversivo do esteta que valoriza a transitoriedade de uma época e a metamorfose de um espaço, ou seja, o esteta insiste em negar artesanalmente os valores inerentes à cultura do sacrifício, a qual exclui de seu sistema todos os que transgridem o ideal de igualdade delimitado por Deus ou pela Razão Universal. Portanto, a existência estética concerniria àquela obra que subverte o jogo entre visibilidade e invisibilidade, isto é, àquela que eleva a prostituta Olympia, até então sem possibilidades de expressão, à categoria de deusa da beleza. Sendo assim, o corpo de Olympia, desnudado e iluminado pelos olhos do pintor e do espectador, deixaria de denotar a decadência e a baixeza de um espírito envelopado por uma vontade proeminentemente somática, e passaria a exprimir experiências plurais advindas de entrecruzamentos furtivos e heterotópicos. Mais precisamente, o corpo de Olympia não representaria mimeticamente a pureza de uma alma divina. Diferentemente, o corpo da prostituta, desnudado toda vez que o espectador a frequenta, performaria de modo agressivo e transgressivo a polêmica de uma verdade que extrai o fugidio do eterno, ou melhor, que extrai a criatividade crítica da morte de Deus e da razão Universal. Isso significa que para Michel Foucault a articulação entre o belo e o bem não se exprime por meio da figura da virgem obediente e dócil, ou seja, a vida estética é rigorosamente ética porque concerne a um esforço crítico e libertário em torno da constituição de si mesmo. ${ }^{5}$

2

Raffaello, Madonna di Pasadena, 1503, 55 X 40cm, Pasadena, Norton Simon Museum.

Tizianno, Venere di Urbino, 1534. 119 X 165 cm, Florenza, Galleria degli Uffizi.

Édouard Manet, Olympia, 1863, 130.5 X 190 cm, Paris, Musée d'Orsay.

Quando nos referimos à ideia de crítica libertária fazemos menção às repercussões das filosofias do período helenístico-romano, assim como interpretadas por Foucault, sobre formas de resistência modernas e contemporâneas que atribuem efetividade política à prática ética, isto é, que compre- 
Por conseguinte, a austeridade relativa à estética da existência se vincularia ao exercício da autarquia ou do domínio de si mesmo. De modo geral, isso significa que a liberdade concerne ao esforço (érgon) que busca transformar ética e politicamente a vida do esteta e o mundo com o qual ele interage. Foucault subverteria a concepção clássica da vida artista na medida em que conceberia a estética da existência como uma atitude artesanalmente libertária, a qual incitaria a criação de modos de vida distintos dos padrões postos pela cultura vigente, esteja ela atrelada ao platonismo, ao aristotelismo, ao código religioso ou às leis civis. Para Foucault a beleza se manifesta na fugaz performance da distinção ética, isto é, na iminência da subversão que decorre de um movimento de recusa da cultura adquirida: "E com isso a arte estabelece com a cultura, com as normas sociais, com os valores e os cânones estéticos uma relação polêmica de redução, de recusa e de agressão.” (FOUCAULT, 2011a, p. 165) A subversão e a transgressão não correspondem a uma negação vazia das instituições vigentes, pelo contrário, elas advêm da crítica. A crítica consiste em um esforço reflexivo e prático que procura desnudar as relações de poder que constituem o corpo social como um todo e o indivíduo como sua parte constituinte. Com efeito, criticar o

endem a potencialidade política da exercitação da amizade ou da experiência da grupalidade, as quais corresponderiam a uma forma de manifestar a escolha autarquicamente constituída por um modo de vida que confronta os padrões e hábitos instituídos no contexto da submissão de si mesmo a certa estrutura hierárquica. Sendo assim, na esteira de Foucault, concebemos que haveria um entrecruzamento transhistórico entre a autarquia helenístico-romana e algumas políticas libertárias de nossa época, as quais não se desenrolam na instância dos poderes hegemônicos e institucionais. As leituras de Foucault acerca da Antiguidade nos inspiram a pensar a resistência sob o espectro da libertação e, se assim for, faz-se importante ressaltar que esta liberdade que se busca não consiste em um estado absolutamente adquirido e garantido pela filosofia, pela religião ou pelo Estado. Não se trata de uma libertação religiosa, como aquela ensejada pelos ascetas que preconizam a renúncia a si, e nem mesmo de uma libertação moral ou democrática. Diferentemente, trata-se de uma libertação estética que articula a urgência da transfiguração de si à urgência da transformação do mundo através do exercício da liberdade de palavra ou da parrehsía, a qual é capaz de expor e contrapor com franqueza as opressões que atingem a razão tanto no que concerne ao indivíduo quanto no tange ao Todo. Nesse sentido, talvez possamos admitir que a crítica é libertária na medida em que nos liberta de nós mesmos, de nosso estado de servidão ou de estultícia. Desse modo, conforme Foucault, a beleza de uma existência esteticamente libertária poderia ser experimentada nas incessantes tentativas de criar uma vida subversiva, cujo estilo decorre da transgressão e não da transcendência ou ultrapassagem de si.Inspirados pelas interpretações de Edson Passetti acerca da amizade (PASSETTI, 2003, p. 65), recorremos alusivamente a Max Stirner, para quem: "A essência da verdade é a revelação de si mesma, ora essa revelação passa pela descoberta de si, pela libertação contra qualquer elemento alheio, pela abstracção extrema ou pela liquidação de toda a autoridade, pela reconquista da ingenuidade." (STIRNER, 1979, p. 81) 
real não corresponde a imitá-lo sacrificialmente, mas sim a transgredi-lo através da violação do vínculo entre austeridade e autoridade Universal. Mais precisamente, o esteta-artesão seria aquele que se torna sua própria autoridade no momento em que, desconfortável com a maneira de governar que institui a cultura do sacrifício, e com o código moral que determina o mesmo modo de vida a todo e qualquer indivíduo, questiona-se: “ 'Como não ser governado dessa forma, por isso, em nome desses princípios, em vista de tais objetivos e por meio de tais procedimentos, não dessa forma, não por isso, não por eles’ "? (FOUCAULT, 1995, p. 7, tradução nossa) Isso significa que a atitude artesanal consiste no esforço crítico que visa modificar completamente o si mesmo de modo a transformá-lo em algo que ele jamais foi. Desse maneira, a estética da existência se distanciaria da concepção de uma vida autêntica que manifestaria o aperfeiçoamento da essência humana. Para Foucault a transgressão possível dos limites absorvidos por determinada cultura consistiria na abertura ao impossível, isto é, na criação artesanal de formas de vida e de experiências mundanas até então irreais ou inimagináveis. Portanto, a beleza da vida libertária se exprime na elaboração ética do si mesmo e na resistência política daquele ou daqueles que não se conformam à esperança em um mundo transcendente, mas antes se dedicam ao esforço que torna urgente a recusa daquilo que somos neste tempo e neste espaço, ou seja, a recusa em relação às formas de governo que reprimem e subordinam os sujeitos, tanto no âmbito individual quanto no coletivo.

\section{BIBLIOGRAFIA}

FOUCAULT, M. A Hermenêutica do Sujeito. Trad. Márcio Alves da Fonseca e Salma Tannus Muchail. São Paulo: Martins Fontes, 2010.

.A Coragem da Verdade. Trad. Eduardo Brandão. São Paulo: Martins Fontes, 2011a.

- A História da Sexualidade 2: O uso dos prazeres. Trad. Maria Thereza da Costa Albuquerque. São Paulo: Graal, 2012.

- A História da Sexualidade 3: O cuidado de si. Trad. Maria Thereza da Costa Albuquerque. São Paulo: Graal, 2011b.

. Dits et écrits II. 1976-1988. Paris: Gallimard, 2001. 
“La peinture de Manet”. In: SAISON, M (Dir.). La peinture de Manet. Suivi de Michel Foucault, un regard. Paris: Seuil, 2004. pp. 21-47.

—_ “¿Qué es la crítica?”. In: Daímon: Revista de Filosofia. Trad. Javier de la Higuera, $1995, \mathrm{pp} \cdot 5^{-25}$

. Segurança, Território e População. Trad. Eduardo Brandão. São Paulo: Martins Fontes, 2008.

LONG, A.A; SEDLEY, D.N. The Hellenistic Philosophers: greek and latin texts with notes and bibliography. Cambridge: Cambridge University Press, 2009. 2v.

HADOT, I; HADOT, P. Apprendre à philosopher dans l'Antiquité: L'enseignement du « $M a-$ nuel d'Épitète » et son commentaire néoplatonicien.Paris: Livre de Poche, 2004.

PASSETTI, E. Éticas dos Amigos.São Paulo: Imaginário, 2003.

STIRNER, M. Textos Dispersos. Trad. José Bragança de Miranda. Lisboa: Via Editora, 1979. 